\title{
AVALIAÇÃO DE DIFERENTES TRATAMENTOS NA GERMINAÇÃO DO CAPIM CAMALOTE
}

\author{
ZERA, Fabricio Simone \\ SCHIAVETTO, Ana Regina
}

AZANIA, Carlos Alberto Mathias ALVES, Pedro Luís da Costa Aguiar

\begin{abstract}
RESUMO: O capim camalote é uma das principais plantas daninhas da cultura da cana-de-açúcar e presente no Brasil em diversos Estados, é uma planta altamente agressiva, prolífica e suas sementes apresentam dormência. Para testar qual o melhor método para quebrar essa dormência foi desenvolvido um experimento com sementes de capim camalote, em câmera de germinação, sob condições climáticas controladas. O delineamento experimental utilizado foi o inteiramente casualizado com quatro repetições. Foram selecionadas 100 sementes em cada repetição. Os tratamentos testados foram 14 diferentes temperaturas mais o controle. Foi avaliada a porcentagem de germinação, velocidade de emergência e o índice de velocidade de emergência, durante 30 dias. Por fim as variáveis quantitativas foram analisadas estatisticamente pela analise de variância e posteriormente suas médias comparadas pelo teste de Tukey a $1 \%$. O trabalho concluiu-se que os tratamentos com temperaturas superiores $\left(50\right.$ e $\left.70{ }^{\circ} \mathrm{C}\right)$ tiveram maior eficiência na quebra da dormência.
\end{abstract}

Palavras-chave: Rottboellia cochinchinensis. Germinação. Emergência

SUMMARY: The Itchgrass is a major weed of cultivation of sugarcane and present in Brazil in several states, is a highly aggressive plant, prolific and their seeds present dormancy. To test the best method to break this dormancy experiment was carried out with itchgrass seed in germination camera under controlled climatic conditions. The experimental design was completely randomized with four replications. We selected 100 seeds in each repetition. The treatments were 14 different temperatures over the control. The percentage of germination was evaluated, emergency speed and the speed of emergence index, for 30 days. Finally the quantitative variables were statistically analyzed by analysis of variance and subsequently their means compared by Tukey test at $1 \%$. The study concluded that the treatment with higher temperatures $\left(50\right.$ and $\left.70^{\circ} \mathrm{C}\right)$ had better efficiency in breaking dormancy.

Keywords: Rottboellia cochinchinensis. Germination. Emergency

\section{INTRODUÇÃO}

O capim-camalote (Rottboellia cochinchinensis) é uma das principais plantas daninhas da cultura da cana-de-açúcar, de origem asiática, esta presente em pelo menos dezoito culturas na África, Ásia, América Central e América do Sul, Estados Unidos, Austrália e Papua Nova Guiné (ANNING; YEBOAH-GYAN, 2007). Nos canaviais brasileiros há ocorrência no Rio de Janeiro (OLIVEIRA; FREITAS, 2008), e também já há relatos de ocorrencia em São Paulo, Paraná e Mato Grosso do Sul (BIANCO et al., 2002).

É uma planta anual ou perene, que se reproduzem tanto pela via seminífera, sementes, com pela vegetativa, caules apresentam gemas nos nós (KISSMAN, 1997). Extremamente competitiva, com características alelopáticas (MEKSAWAT; PORNPROM, 2010), muito vigorosa e prolífica, sendo que uma única planta pode emitir até 100 perfilhos e produzir de 2.200 até 16.500 sementes (HALL;

\footnotetext{
${ }^{1}$ Engenheiro Agrônomo, graduado pela Universidade Federal de Viçosa - UFV, mestrado pelo Instituto Agronômico - IAC na área da Tecnologia da Produção Agrícola, e doutorando pela UNESP de Jaboticabal na área da Produção de Vegetal.
} 
PATTERSON, 1992). Entretanto, a contribuição das sementes para o banco de sementes é muito menor do que pode ser estimado pela produção por planta. Em um trabalho apresentado por Smith et al. (2001), na Costa Rica, por exemplo, a contagem de sementes no início da safra forneceu a média de 324 sementes $\mathrm{m}^{-2}$.

Suas sementes podem ficar dormentes no solo por até quatro anos. Estas podem ficar superficialmente ou enterradas, de 5 a $10 \mathrm{~cm}$ de profundidade ou até $20 \mathrm{~cm}$ de profundidade. Outro agente indutor de dormência em suas sementes é provocado pela presença do frio (BRIDGEMOHAN et al., 1991). Segundo Monquero et al. (2012) devido suas sementes se encontrarem em profundidades maiores no solo, provocam futuras infestações, pois nessas condições as sementes persisti por mais tempo.

A dormência das sementes de Rottboellia cochinchinensis e seus padrões de germinação variam substancialmente nas diversas regiões do mundo (HOLM et al., 1977). Segundo Bridgemohan et al. (1991), na cultura do milho, de 40 a $60 \%$ das sementes podem persistir no solo após um ano do cultivo, com a dormência inata e induzida contribuindo com 8,5 e 35\%, respectivamente.

Na Costa Rica, Rojas et al. (1994) demonstraram que algumas sementes permaneceram viáveis após 18 meses de enterrio no solo. Regimes de temperatura, de luz, umidade e tratamentos químicos, entre os quais a aplicação de nitrato de potássio, são fatores que afetam a germinação de sementes (POPINIGIS, 1985); além disso, podem revelar diversos mecanismos de dormência, exigindo técnicas específicas para sua superação (KHAN, 1977). Segundo Hall e Patterson (2013) a umidade é um fator importante na quebra da dormência das sementes de capim-camalote, solos mais secos tendem ter um desenvolvimento mais lento. Eles também relataram que temperaturas baixas limitam o desenvolvimento do capimcamalote. Para Etejere e Ajibola (1991), a germinação das sementes de capim-camalote pode ser aumentada pela exposição ao calor seco $\left(80^{\circ} \mathrm{C}\right)$ por um minuto, em concentrações variando entre $100 \mathrm{e}$ 500 ppm de ethephon, dos seguintes compostos: acido indol-3-acético, tioureia, nitrato de potássio ou tiosulfato de sódio por 24 horas, ou, ainda, imersão em água corrente, ácido sulfúrico ou clorídrico ou nítrico por 1 a 25 minutos.

Devido a sua agressividade nos canaviais, Lorenzi (1983) relatou redução de $80 \%$ na produtividade em soqueiras, e de 100\% em cana-planta (ARÉVALO; BERTONCINI, 1994), quando em elevada infestação. Segundo Holm et al. (1977) a interferência do capim-camalote nos canaviais não permite o fechamento da entrelinha da cultura, em situações de densidades maiores que 10 plantas por $\mathrm{m}^{2}$. Considerando que o capim-camalote está infestando lavouras no Brasil e que apresenta elevada agressividade associada a um difícil controle, particularmente na cultura da cana-de-açúcar, qualquer conhecimento adicional sobre a biologia dessa espécie proporcionará maiores subsídios para o seu manejo nas nossas condições. Com este trabalho, objetivou-se estudar tratamentos úmidos com diferentes temperaturas na quebra da dormência em sementes de capim-camalote (R.cochinchinensis).

\section{MATERIAL E MÉTODO}

O experimento foi desenvolvido no período de junho/julho de 2014 com a espécie de $R$. cochinchinensis, em câmera de germinação tipo BOD, sob condições climáticas controladas que possibilitam simular em laboratório características térmicas e inserção de luz tanto do dia, quanto da noite. O ensaio foi conduzido por 30 dias sob as condições $30 / 15{ }^{\circ} \mathrm{C}$ (diurna/noturna) para um fotoperíodo de $14 / 10$ horas.

O delineamento experimental utilizado foi o inteiramente casualizado com quatro repetições. Foram selecionadas 100 sementes em cada repetição, essas adquiridas por uma empresa especializada no segmento, e colocadas em caixas plásticas gerbox, com a capacidade $250 \mathrm{~mL}$ e de medida 11 x 11 x 3,5 
$\mathrm{cm}$. Os tratamentos testados seguem a seguir na Tabela 1 .

A espécie também tiveram suas sementes caracterizadas quanto à viabilidade do lote, escolhendose ao acaso 200 sementes que foram distribuídas em quatro repetições de 50 sementes cada. As sementes foram cortadas longitudinalmente e acondicionadas dentro de recipientes de vidro âmbar acrescidos de solução de 2,3,5-trifenil cloreto de tetrazólio a $0,1 \%$. Os recipientes foram colocados no escuro durante 8 horas, posteriormente realizou-se a contagem do número de sementes com embriões coloridos de rósea (BRASIL, 2009). No final constatou-se a porcentagem de viabilidade do lote de R.cochinchinensis que foi de $98 \%$.

Tabela 1. Tratamentos para quebra de dormência de R. cochinchinensis. 2014

\begin{tabular}{cl}
\hline & \multicolumn{1}{c}{ TRATAMENTOS } \\
\hline T1 & Controle \\
T2 & Sementes passada na água à $70^{\circ} \mathrm{C}$ durante 10 segundos \\
T3 & Sementes permanecem 30 minutos na água à $70^{\circ} \mathrm{C}$ \\
T4 & Sementes passada na água à $50^{\circ} \mathrm{C}$ durante 10 segundos \\
T5 & Sementes permanecem 30 minutos na água à $50^{\circ} \mathrm{C}$ \\
T6 & Sementes permanecem 30 minutos na água \\
T7 & Sementes permanecem 1 hora na água \\
T8 & Sementes permanecem 6 horas na água \\
T9 & Sementes permanecem 10 horas na água \\
T10 & Sementes permanecem 24 horas na água \\
T11 & Sementes passada na água gelada durante 10 segundos \\
T12 & Sementes permanecem 30 minutos na água gelada \\
T13 & Sementes permanecem 5 minutos no congelador \\
T14 & Sementes permanecem 15 minutos no congelador \\
T15 & Sementes permanecem 30 minutos no congelador \\
\hline
\end{tabular}

Todos os tratamentos foram utilizados um termômetro a fim de averiguar a temperatura desejada. Para atingir as temperaturas $70^{\circ}$ e $50^{\circ} \mathrm{C}$, foi utilizado um ebulidor elétrico de aquecedor de água.

Foi avaliada a porcentagem de germinação, para isso, foram contadas as sementes germinadas diariamente, até a estabilização da germinação das mesmas, o que levou em torno de 30 dias, considerando-se sementes germinadas as que apresentaram plântula normal as que tinham as estruturas essenciais do embrião desenvolvidas. Foram contadas todas as sementes emergidas diariamente durante os 30 dias e após calculada a porcentagem. Também foram avaliados a velocidade de emergência (VE) e o índice de velocidade de emergência (IVE), os quais estimaram, respectivamente, o número médio de dias necessários para a ocorrência da emergência e o número médio de plântulas normais emergidas por dia (ÁVILA et al., 2005).

A velocidade de emergência foi avaliada por meio da contagem das plântulas emergidas durante os 30 dias após a semeadura (DAS). As fórmulas usadas para cálculo do IVE e VE foram propostas por Maguire (1962), as quais são apresentadas a seguir: IVE $=(\mathrm{G} 1 / \mathrm{N} 1)+(\mathrm{G} 2 / \mathrm{N} 2)+\ldots+(\mathrm{Gn} / \mathrm{Nn})$, em que: IVE $=$ índice de velocidade de emergência; $\mathrm{G}=$ número de plântulas normais computadas nas contagens; $\mathrm{N}=$ número de dias da semeadura à $1^{\mathrm{a}}, 2^{\mathrm{a}} \ldots 30^{\mathrm{a}}$ avaliação. Para Maguire (1962), o cálculo da velocidade de emergência (VE) é realizado com os dados utilizados para o cálculo do IVE, utilizando-se a fórmula proposta: $\mathrm{VE}=[(\mathrm{N} 1 \mathrm{G} 1)+(\mathrm{N} 2 \mathrm{G} 2)+\ldots+(\mathrm{NnGn})] /(\mathrm{G} 1+\mathrm{G} 2+\ldots+\mathrm{Gn})$, em que: $\mathrm{VE}=$ velocidade de 
emergência (dias); $\mathrm{G}$ =número de plântulas emergidas observadas em cada contagem; $\mathrm{N}$ = número de dias da semeadura a cada contagem.

As variáveis quantitativas relacionadas com germinação das sementes foram analisadas estatisticamente com a aplicação do teste $\mathrm{F}$ sobre a análise da variância. E por fim os dados foram submetidos suas as médias comparadas pelo teste de Tukey, ao nível de $1 \%$ de significância, para isto utilizamos o programa estatístico SASM-Agri: Sistema para análise e separação de médias em experimentos agrícolas.

\section{RESULTADO E DISCUSSÃO}

Analisando os dados do experimento, as sementes apresentaram um período médio de germinação de vinte dias, e a maioria das sementes germinaram nos primeiros dez dias. A porcentagem de germinação foi de, em média, 38,77\%, com o IVE de 3,76, pelo fato da maioria das sementes germinarem até o décimo quinto dia.

Foi observado que sementes tratadas não tiveram diferença em relação à variável germinação pelos tratamentos recebidos, conforme Tabela 2, tantos os dados normais (\%) como os transformados $(\operatorname{raiz}(x+0,5))$.

Tabela 2. Resultados dos testes de Germinação, Índice de Velocidade de Emergência (IVE) e Velocidade de Emergência (VE). 2014.

\begin{tabular}{|c|c|c|c|c|c|c|c|c|}
\hline \multirow{2}{*}{ TRATAMENTOS } & \multicolumn{4}{|c|}{ GERMINAÇÃO(\%) } & \multirow{2}{*}{\multicolumn{2}{|c|}{ IVE }} & \multirow{2}{*}{\multicolumn{2}{|c|}{$\begin{array}{c}\mathbf{V E} \\
\text { (dias) }\end{array}$}} \\
\hline & \multicolumn{2}{|c|}{$\begin{array}{c}\text { Dados } \\
\text { Originais }\end{array}$} & \multicolumn{2}{|c|}{$\begin{array}{c}\text { Dados } \\
\text { Transformados }\end{array}$} & & & & \\
\hline T1 & 32,25 & $\mathrm{a}$ & 5,70 & $\mathrm{a}$ & 3,69 & $\mathrm{~b}$ & 9,46 & $\mathrm{a}$ \\
\hline $\mathrm{T} 2$ & 32,50 & $\mathrm{a}$ & 5,70 & $\mathrm{a}$ & 1,91 & $\mathrm{a}$ & 19,69 & $\mathrm{c}$ \\
\hline $\mathrm{T} 3$ & 35,25 & $\mathrm{a}$ & 5,92 & $\mathrm{a}$ & 1,82 & $\mathrm{a}$ & 20,53 & $\mathrm{c}$ \\
\hline $\mathrm{T} 4$ & 47,25 & $\mathrm{a}$ & 6,90 & $\mathrm{a}$ & 2,91 & $\mathrm{a}$ & 17,10 & b \\
\hline $\mathrm{T} 5$ & 29,00 & $\mathrm{a}$ & 5,40 & $\mathrm{a}$ & 1,53 & $\mathrm{a}$ & 19,87 & $\mathrm{c}$ \\
\hline T6 & 44,50 & $\mathrm{a}$ & 6,66 & $\mathrm{a}$ & 4,57 & $\mathrm{~b}$ & 11,54 & $\mathrm{a}$ \\
\hline $\mathrm{T} 7$ & 39,75 & $\mathrm{a}$ & 6,32 & $\mathrm{a}$ & 4,16 & $\mathrm{~b}$ & 11,22 & $\mathrm{a}$ \\
\hline $\mathrm{T} 8$ & 40,25 & $\mathrm{a}$ & 3,36 & $\mathrm{a}$ & 4,63 & $\mathrm{~b}$ & 9,71 & $\mathrm{a}$ \\
\hline T9 & 40,75 & $\mathrm{a}$ & 6,40 & $\mathrm{a}$ & 4,52 & $\mathrm{~b}$ & 10,43 & $\mathrm{a}$ \\
\hline $\mathrm{T} 10$ & 34,50 & $\mathrm{a}$ & 5,91 & $\mathrm{a}$ & 3,99 & $\mathrm{~b}$ & 9,82 & $\mathrm{a}$ \\
\hline $\mathrm{T} 11$ & 42,50 & $\mathrm{a}$ & 6,54 & $\mathrm{a}$ & 4,32 & $\mathrm{~b}$ & 10,97 & $\mathrm{a}$ \\
\hline $\mathrm{T} 12$ & 50,00 & $\mathrm{a}$ & 7,03 & $\mathrm{a}$ & 5,32 & $\mathrm{~b}$ & 10,72 & $\mathrm{a}$ \\
\hline $\mathrm{T} 13$ & 41,75 & $\mathrm{a}$ & 6,48 & $\mathrm{a}$ & 4,43 & b & 10,56 & $\mathrm{a}$ \\
\hline $\mathrm{T} 14$ & 43,00 & $\mathrm{a}$ & 6,58 & $\mathrm{a}$ & 4,63 & $\mathrm{~b}$ & 10,30 & $\mathrm{a}$ \\
\hline $\mathrm{T} 15$ & 28,28 & $\mathrm{a}$ & 4,99 & $\mathrm{a}$ & 3,94 & $\mathrm{~b}$ & 11,24 & $\mathrm{a}$ \\
\hline Média & 38,7 & & 6 , & & 3, & & & \\
\hline DMS & 25,4 & & 2, & & 2, & & & \\
\hline CV (\%) & 25,7 & & 14 & & 21 , & & & \\
\hline F calculado & 1,71 & & 1,5 & & 8,50 & & 35,7 & \\
\hline
\end{tabular}

IVE (Índice de Velocidade de Emergência); VE (Velocidade de Emergência); ** (significativo a $1 \%$ de probabilidade pelo teste F); ns (não significativo); CV (coeficiente de variação); DMS (diferença mínima significativa); Dados transformados em $\sqrt{ }(x+0,5)$.

No índice de velocidade de emergência, os tratamentos $\mathrm{T} 2$ (Sementes passada na água à $70^{\circ} \mathrm{C}$ ), $\mathrm{T} 3$ (Sementes permanecem 30 minutos na água à $70^{\circ} \mathrm{C}$ ), $\mathrm{T} 4$ (Sementes passada na água à $50^{\circ} \mathrm{C}$ ) e $\mathrm{T} 5$ (Sementes permanecem 30 minutos na água à $50^{\circ} \mathrm{C}$ ) apresentaram o menor índice de velocidade de 
emergência, enquanto os outros tratamentos foram superiores para essa variável estudada, demonstrando ser o mais eficiente segundo a avaliação, destaque para o tratamento 12 que obteve o maior índice $(5,32)$, porem estatisticamente não diferiu dos demais.

$\mathrm{Na}$ avaliação do teste de velocidade de emergência das plântulas, observou-se que os tratamentos T2, T3 e T5 foram considerados de menor vigor, apresentando maior número de dias para a emergência média das plântulas seguido pelo tratamento T4, enquanto que os outros tratamentos foram considerados de maior vigor. Quanto menor o valor obtido pela fórmula de velocidade de germinação ou emergência têm-se tratamentos de sementes com maior potencial fisiológico Edmond e Drapala (1958).

A temperatura é considerada um requerimento para a germinação de sementes (PATTERSON et al., 1979). Assim, quando as sementes de capim camalote foram submetidas a diferentes temperaturas, constatou-se que temperaturas mais elevadas $\left(50\right.$ e $\left.70{ }^{\circ} \mathrm{C}\right)$ encontrou mais eficiente na quebra da dormência, enquanto que em temperaturas inferiores as sementes mostraram-se mais resistente na quebra da dormentes. O que confere com dados observados por Silva et al. (2009) onde as temperaturas superiores $\left(25^{\circ} \mathrm{C}\right)$ teve melhor germinação diante das temperaturas inferiores $\left(10^{\circ} \mathrm{C}\right)$. E Martins e Silva (2001) obtiveram redução da taxa de dormência de sementes de Braqhiaria brizanta cultivar Marandu com tratamento térmico de $70{ }^{\circ} \mathrm{C}$ a 10 e 15 horas.

\section{CONCLUSÃO}

Por meio desse resultado é possível inferir que não houve diferença na germinação das sementes de capim-camalote, o que se observou foi que além da umidade, os tratamentos que tiveram temperaturas superiores $\left(50\right.$ e $\left.70^{\circ} \mathrm{C}\right)$ foram mais eficientes na quebra da dormência, já que proporcionaram uma emergência mais rápida das plântulas em estudo.

\section{REFERÊNCIAS}

ANNING A.K.; YEBOAH-GYAN, K. Diversity and distribution of invasive weeds in Ashanti Region, Ghana. African Journal of Ecology, v.45, n.3, p.355-360, 2007.

ARÉVALO R. A.; BERTONCINI, E. I. Biologia e manejo de Rottboellia exaltata na cultura da canade-açúcar Saccharum spp.: análise do problema. Piracicaba: Estação Experimental de cana-de-açúcarIAC, 1992. $42 \mathrm{p}$.

ÁVILA, M. R. et al. Testes de laboratório em sementes de canola e a correlação com a emergência das plântulas em campo. Revista Brasileira de Sementes, v. 27, n. 1, p. 62-70, 2005.

BRASIL. Ministério da Agricultura e Reforma Agrária. Regras para análise de sementes. Brasília: LAVARV/SNAD, 2009. $365 \mathrm{p}$.

BRIDGEMOHAM, P.; BRATHWAITE, R. A. I.; MAC DAVI, C. R. Seed survival and patterns of seedling emergence studies of Rottboellia cochinchinensis Clayton in cultivated soils. Weed Research, v. 31, n. 5, p. 265-72, 1991.

BRIDGEMOHAN, P. et al. The effects of Rottboellia cochinchinensis on the growth, development and yield of maize. Tropical Pest Management, v. 38, n. 4, p. 400-407, 1992.

EDMOND, J.B.; DRAPALA, W.J.The effects of temperature, sand and soil, and acetone on germination of okra seeds.Proceedings of American Society of Horticultural Science, Alexandria, v.71, n.2, p.428434, 1958. 
ETEJERE, E. O.; AJIBOLA, I. O. Studies on seed germination and dormancy of Itchgrass (Rottboelliaexaltata). Nig. J. Weed. Science, v. 3, v. 1, p.19-28, 1991.

HOLM, L. G.; PLUCKNETT, D. L.; PANCHO, J. V.; HERBERGER, J. P.The world's worst weeds distribution and biology. Honolulu: University Press, 1977. 609 p.

KHAN, A. A. The physiology and biochemistry of seed dormancy and germination. Amsterdam: Elsevier/North-Holland, 1977. $447 \mathrm{p}$

KISSMANN, C.G. Plantas infestantes e nocivas. t.I - Plantas inferiores; monocotiledôneas - $2^{\mathrm{a}}$. ed. São Paulo: BASF, 1997. 825p.

LORENZI, H. Plantas daninhas do Brasil: terrestres, aquáticas parasitas e tóxicas. 3.ed. Nova Odessa: Plantarum, 2000. 608 p.

MARTINS, L.; SILVA, W. R. Comportamento da dormência em sementes de braquiária submetidas a tratamentos térmicos e químicos. Pesquisa Agropecuária Brasileira, v. 36, n. 7, p. 997-1003, 2001.

MEKSAWAT, S.; PORNPROM, T. Allelopathic effect of itchgrass (RottboelliaexaltataL.f.) on seed germination and plant growth.Weed Biology and management, v.10, n.14, p.16-24, 2010.

OLIVEIRA, A. R.; FREITAS, S. P. Levantamento fitossociológico de plantas daninhas em áreas de produção de cana-de-açúcar. Planta Daninha, v.26, n.1, p.33-46, 2008.

PATTERSON, D. T. et al. Temperature responses and potential distribution of itchgrass (Rottboelliaexaltata) in the United States. Weed Science, v.27, n. 1, p.77-82, 1979.

POPINIGIS, F. Fisiologia da semente. 2.ed. Brasília: 1985. 289 p.

ROJAS, C. E.; DE LA CRUZ, R.; MERAYO, A. La profundidad y duraciónenelsuelo de lasemilla de caminhadora (Rottboelliacochinchinensis (Lour.) Clayton) y suefecto sobre laviabilidad y persistenciaenel trópico seco. Manejo Integrado de Plaga, v.32, p. 25-29, 1994.

SILVA, C.E.B., PARREIRA, M.C., ALVES, P.L.C.A. e PAVANI, M.C.M.D. Aspectos Germinativos de Capim Camalote (Rottboellia cochinchinensis). Planta Daninha, v. 27, n. 2, p. 273-281, 2009.

SMITH, M. C. et al. Integrated management of itchgrass in a corn cropping system: Modelling the effect of control tactics. Weed Science, v.49, n. 1, p. 123-134, 2001. 